\title{
Improve Higher Vocational Students' Ability to Read Texts in the Classroom
}

\author{
Yanli Wang \\ Wuhan Urban Institute of Primary Education 430063
}

472207066@qq.com

Keywords: Reading skills; Autonomous learning; Reading efficiency

\begin{abstract}
The ability to read is an important era of knowledge economy, the stronger reading skills, the stronger the self-learning ability in the future, the higher the quality of life. Based on the characteristics of elementary school students for future primary school language teachers groups primary Chinese education professional, combined with primary school language teaching materials, a method designed to enhance students 'ability to read the text, to improve students' reading efficiency and quality in the classroom teaching purposes.
\end{abstract}

\section{Introduction}

Extracurricular Reading Is to Expand and Extend Curricular Reading Language Learning Outside the Classroom Is to Improve Students' Language Proficiency Plays An Important Role A wide range of extracurricular reading for students will get information pluralism, broaden their horizons, enrich knowledge, improve language literacy play a positive role in promoting "teach him to fish to fish, teachers should give full play to classroom teaching as a delegate, to carry out scientific and reasonable reading guidance, driven by the curricular and extra-curricular, extra-curricular curricular rich, so as to achieve the purpose of reading. so, how teachers should strengthen the guidance in the classroom, leading the reader into the students' self. I thought they could start from the following aspects

\section{You Begin to Develop the Habit of Reading, Students Analyze Perception}

Pupils read to do mouth to hand to the heart to the eye. Teachers should pay attention in the classroom teaching guide, encourage and strengthen the students to develop "reading pen to paper" a good habit to improve reading efficiency. The so-called "pen to paper reading" means reading from side to side with a particular symbol for comments and do reading notes in the text, or punctuate outline Key words, or label feelings, or daring to question, or excerpt good words, or write their feelings and experiences etc., and text-depth dialogue in the book left to read self-blot.

First, in the classroom, teachers should pay attention to guide students to use a variety of forms to write to annotate. (1) text annotation teachers should guide students while reading, while in between the lines of text with a brief write your own experience after reading the text, comment, question, etc. (2) symbol notation. Annotation symbols have to draw lines (single horizontal line, two horizontal lines, and wavy lines), parentheses, circle, dot, triangle sign, question mark, exclamation point, these symbolic forms, but simple, easy to use, communication and memory. Particularly suited for low-grade students. Such as a simple circle drawing little circles like fallible words, sentences like painting, standard number of sentences and so on. In the classroom, I pay attention to guide students to form their own reading conventional symbols in the process of reading the text, the formation of habits. As the focus of the underlined sentences, key words subscript, and superscript doubt place a question mark, exclamation point marked wonderful place and so on. (3) Title annotation. In teaching, teachers can guide students to list the main content of the text form of sub-headings in the text blank, paragraphs outline, etc., and to develop teaching methods subtitled, with clear and concise statement that summarizes the paragraph is intended to do subtitled; pick out the best expression of the central section of the phrases or words for the sub-title, so that students overall perception of the text, and then effectively read. Such as teaching "climb the Heavenly 
Capital Peak" Keqianyu xi Guidance case design, I like this design: marked paragraphs; outline new vocabulary words; do not know the words ring out and do not understand the words, and by finding tool books, etc. to solve; ponder what the text speaks, do not understand the tag number in place; gather information and Heavenly Capital Peak circle draw focus. In teaching sixth and seventh paragraphs, I like this design. Allow students the freedom to read aloud the sixth, seventh paragraph, while being read to draw you the most moving statement, written on next experience. According to statements of students, the students praise, encourage students to good study habits to extracurricular reading.

We begin reading teachers guide students to develop reading habits, not only to help students better understand and remember, but also to enhance the reader's ability to analyze sentiment, lay a good foundation for lifelong reading.

\section{To Guide Students to Master the Method, Pay Attention to Reading Efficiency}

A philosopher once said: "There is no proper method, even if there are pundits of the eye, like the blind groping as the blind." Therefore, teachers should guide students based on the content of books, reading their own purposes, interests and level of understanding of different, choose different reading methods, such as read, intensive reading, skimming, Readings, video, silent reading, reading, extensive reading, browsing flexible self-service.

Silent reading aloud is not visual, not only visual breadth big, fast reading speed, but also contribute to understanding and thinking, improve reading efficiency. In addition to poetry, in general access to information, reading newspapers and books, and other method has been applied. Usually when reading newspapers and read through that quickly browse a newspaper picture, understand the general content, a "bird's eye panorama" effect, and then selectively peruse. If you gather information, you can use extensive reading and speed reading methods to improve the ability to find information filtering and screening speed. Reading a famous masterpiece, teachers can guide students to "rough reading - Intensive - reading" This program attempts. First, let the students read the full text of crude, with books, text clearing obstacles, the overall perception of the main contents of the article, clarify the context level. Then let the students devote themselves to peruse, questioning doubts, deep thinking, try to figure out the focus of the paragraph statement, understand the thoughts and feelings and writing methods. Finally, let students into the familiar chant, the students understand the basis of the article on, with emotion, read with appreciation, in particular those paragraphs the text quality and beauty but also to reach into the familiar chant, but also allows students to extract phrasebook write book review, etc., to make it into their own language, so that it can come in handy when writing the description needs, flexible application. Teachers can take advantage of the teaching of reading the text to guide students to become familiar with and implement the "crude read - Intensive - reading" This is a reading program. Such as teaching fifth grade of "Osman thus Rain", the teacher may be designed to read these four steps. First read the text, perception effect. Close reading of the text, and understand the wording. Feelings of reading, into a familiar chant. Enhance the classroom, when the Church training mode.

In short, reading methods are diverse, different style of reading method reading materials chosen is different. Teachers in the classroom teaching should strengthen the guidance to lead, to equip students with a variety of reading and flexible application of methods and techniques to improve reading efficiency.

\section{To Enhance the Teaching Ability to Stimulate Students' Interest in Reading}

Each book in the language of a text are carefully selected out of an excellent article. Thus, each lesson is a combination of all extra-curricular knowledge; there are opportunities for extracurricular reading. Teachers should make full use of textbooks, textbook as a starting point, there are plans to do before or after school reading lead, before and after-school inspired encourage students to read the relevant knowledge, broaden their horizons, make curricular and extra-curricular reading "take off together . "Teachers according to the content of textbooks, the actual situation of the students, 
flexibility to choose the appropriate way to lead, in order to achieve a multiplier effect. And this leads to read, teachers are required to have deep cultural heritage need to pay attention to skills.

Teaching "Cao chuanjiejian" I used the "fan worship, Chengdu style" reading lead the way. I was full of students advance to the magic figure of Zhuge Liang charm, stimulate students interest in reading: "He's resourceful, his crafty plan; he, Shangzhi astronomy Xiao geography; he Caochuanjiejian Huoshao chi bi; his three Zhou Yu's ghost town meter, a plan even a plan, a meter connected to a meter, meter without false hair, all seek in. who is he? he is the Three Kingdoms period of Shu "spared no efforts in dying "Zhuge Liang" this means we have to learn about he his crafty plan of a text "Caochuanjiejian." You want to know him? He has what story? Please read the "Three Kingdoms." "After listening to Teacher's remarks, students Zhuge Liang worship like the endless rolling river, cannot wait to go to borrow. Teachers can also remind students to peruse the" Three Kingdoms "42 back to 46 back, to understand what was Wei, Shu and Wu Sanguo situation of Zhuge Liang and Zhou Yu Why jealousy, learning to lay groundwork for the text when teaching "Junior Run soil," I used the "clever set up suspense, stimulate interest," read to lead the way. I'll courseware production midlife RunTu and juvenile RunTu picture, so that students guess the two of them relationship in a buzz students know the truth, I began to inspire students to "look how healthy, smart, lovely boy RunTu ah, but then, it completely changed, becoming numb expression, taciturn. This in the end is why? Want to know the answer? Please read Lu Xun wrote, "Home." Students' curiosity was aroused in an instant, desire to read up flood surge. Lead by purposeful reading, so that students and interest into targeted extracurricular reading activities, both to consolidate and enhance the curricular knowledge, but also cultivate self-learning ability.

\section{The Development of Effective Mechanisms to Promote Students to Develop Reading Habits}

Teachers need to develop some regular reading program for students to ensure that students effective reading time, encourage students to develop good reading habits. As teachers to extracurricular reading as part of classroom teaching, the students form the good habit of daily reading; build a platform to encourage students to read effectively. Plenty of reading time is to ensure the quality of extracurricular reading of an important condition. So, I put extracurricular reading as a language of work, every night unshakeable arranged a "read half-hour" of operation, so that students have enough time to read, and to develop the accompanying book, and books as well as good habits. Every week I take full advantage of speaking lessons, self-study courses, school-based curriculum and extra-curricular time for students to extracurricular reading books or collective exchange book review, in the classroom so that they can actually feel the pleasure of reading, book and enjoy surfing in the sea like pleasure.

In addition to developing reading programs, but to create an effective evaluation mechanism, "because there are objective, so harder; because recognition and praise, the more confident," according to the psychological characteristics of students, I often carry out study exchanges, speech contests in the classroom, essay competition and a series of colorful reading activities, according to the results of the competition, named "reading Star" "Speaker wit" "Young writers" and so on. Read good books, good reading, there is a corner of the classroom, "read the contest" records, according to their own students to study in the Form their own reading head, published a month ago to study the top ten, giving recognition awards, to promote students persevere reading "I have also asked students in reading, excerpt good words, good words, good segment, famous aphorism, regular reporting on the class reading lesson to share with you, this form of greatly improving the quality of students' reading.

Thus, the display reading for students to build a platform to create effective evaluation mechanisms, so that students feel in school activities have obtained fun reading test results, found that reading deficiencies, weaknesses and progress. 


\section{Conclusion}

Class students to read the text. Teachers take classroom instruction and extracurricular reading organically linked, so that students are widely and effectively extracurricular reading, improve language literacy, broaden their horizons, and strive to create a good quality and healthy personality.

\section{Acknowledgement}

Projects: Articles for Wuhan Gaojiao Chu teaching reform project "context of information technology, the students read the text Vocational College Situation and Countermeasures Analysis -A Chinese city of Wuhan Institute of Vocational Education as an example," one $(2,014,176)$ initial results

\section{References}

[1] Qian LiqunQian Liqun Chinese Education New Theory [M] Shanghai: East China Normal University Press, 2010.

[2] Lai neoclassical classroom [M] Beijing: Education Science Press, 2009.

[3] Qing Classic often talk about [M] Guilin: Guangxi Normal University Press, 2010.

[4] Caoming Hai, Xiu-Qing Zhang language education and cultural process research [M] Jinan: Shandong People's Publishing House, 2005.

[5] Fang Zhifan language education and literacy literature [M] Guangzhou: Guangdong Education Publishing House, 2005.

[6] Wang Rong sheng language teaching content Reconstruction [M] Shanghai: Shanghai Education Publishing House, 2007. 